\title{
Myocardial tissue elastic properties determined by atomic force microscopy after stromal cell-derived factor $1 \alpha$ angiogenic therapy for acute myocardial infarction in a murine model
}

\author{
William Hiesinger, MD, ${ }^{a}$ Matthew J. Brukman, PhD, ${ }^{\mathrm{b}}$ Ryan C. McCormick, BS, ${ }^{\mathrm{a}}$ J. Raymond Fitzpatrick

 \\ Mark F. Berry, MD, ${ }^{\mathrm{c}}$ Pavan Atluri, MD, ${ }^{\mathrm{a}}$ and Y. Joseph Woo, $\mathrm{MD}^{\mathrm{a}}$
}

\begin{abstract}
Objectives: Ventricular remodeling after myocardial infarction begins with massive extracellular matrix deposition and resultant fibrosis. This loss of functional tissue and stiffening of myocardial elastic and contractile elements starts the vicious cycle of mechanical inefficiency, adverse remodeling, and eventual heart failure. We hypothesized that stromal cell-derived factor $1 \alpha$ (SDF-1 $\alpha)$ therapy to microrevascularize ischemic myocardium would rescue salvageable peri-infarct tissue and subsequently improve myocardial elasticity.
\end{abstract}

\begin{abstract}
Methods: Immediately after left anterior descending coronary artery ligation, mice were randomly assigned to receive peri-infarct injection of either saline solution or SDF- $1 \alpha$. After 6 weeks, animals were killed and samples were taken from the peri-infarct border zone and the infarct scar, as well as from the left ventricle of noninfarcted control mice. Determination of tissues' elastic moduli was carried out by mechanical testing in an atomic force microscope.

Results: SDF- $1 \alpha$-treated peri-infarct tissue most closely approximated the elasticity of normal ventricle and was significantly more elastic than saline-treated peri-infarct myocardium $(109 \pm 22.9 \mathrm{kPa}$ vs $295 \pm 42.3$ $\mathrm{kPa} ; P<.0001)$. Myocardial scar, the strength of which depends on matrix deposition from vasculature at the peri-infarct edge, was stiffer in SDF- $1 \alpha$-treated animals than in controls $(804 \pm 102.2 \mathrm{kPa}$ vs $144 \pm 27.5$ $\mathrm{kPa} ; P<.0001)$.
\end{abstract}

Conclusions: Direct quantification of myocardial elastic properties demonstrates the ability of SDF- $1 \alpha$ to reengineer evolving myocardial infarct and peri-infarct tissues. By increasing elasticity of the ischemic and dysfunctional peri-infarct border zone and bolstering the weak, aneurysm-prone scar, SDF- $1 \alpha$ therapy may confer a mechanical advantage to resist adverse remodeling after infarction. (J Thorac Cardiovasc Surg 2012;143:962-6)

Current therapies for ischemic heart disease consist of pharmacologic optimization and limited revascularization, reconstructive, or replacement options. These modalities, however, are effective for only a fraction of patients. Also, they address neither the significant microvascular

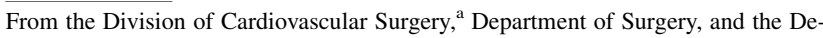
partment of Materials Science and Engineering, ${ }^{\mathrm{b}}$ University of Pennsylvania, Philadelphia, Pa; and the Department of Surgery, ${ }^{\mathrm{c}}$ Duke University, Durham, NC.

Supported in part by National Institutes of Health grant 1R01HL089315-01 (to Y.J.W.), National Institutes of Health and Thoracic Surgery Foundation for Research and Education grant K08 HL072812 (to Y.J.W.), a Thoracic Surgery Foundation Research Award (to W.H.), and National Institutes of Health grant T32-HL-007843-13 (to W.H.). This research was partially supported by the University of Pennsylvania Nano/Bio Interface Center through the National Science Foundation Nanoscale Science and Engineering Center grant DMR08-32802. Use of Nano/Bio Interface Center instrumentation is acknowledged.

Disclosures: Authors have nothing to disclose with regard to commercial support.

Read at the 37th Annual Meeting of The Western Thoracic Surgical Association, Colorado Springs, Colorado, June 22-25, 2011.

Received for publication June 21, 2011; revisions received Nov 22, 2011; accepted for publication Dec 14, 2011; available ahead of print jan 24, 2012.

Address for reprints: Y. Joseph Woo, MD, 3400 Spruce St, 6 Silverstein, Philadelphia, PA 19104 (E-mail: wooy@uphs.upenn.edu).

0022-5223/\$36.00

Copyright (c) 2012 by The American Association for Thoracic Surgery doi:10.1016/j.jtcvs.2011.12.028 deficiencies that persist even when an occluded artery is stented or bypassed nor the abnormal mechanical stress and loading of the infarct and perfused viable border zone region adjacent to the infarct.

It has been shown that immediately after the onset of ischemia, abnormal ventricular loading results in thinning and stretching of the infarct, as well as increased mechanical stress in the peri-infarct border zone. In addition, it has been demonstrated experimentally that infarct expansion is associated with progressive loss of contractile function in the perfused border zone adjacent to the infarct and that this dysfunctional region becomes more hypocontractile and begins to involve additional perfused myocardium as remodeling continues and heart failure progresses. ${ }^{1,2}$ Also, after an infarction, the extent of microvascular obstruction increases greatly during the first 48 hours, and there is significant progressive microvascular and myocardial injury well beyond the infarct zone, even with reperfusion. ${ }^{3,4}$ This is important because an increase in the number of capillaries has been correlated with increases in both contractility and function under stress conditions. ${ }^{5}$ Endogenous repair machinery is inadequate to correct this deficiency, and tremendous resources have 


\section{Abbreviation and Acronym}

SDF- $1 \alpha=$ stromal cell-derived factor $1 \alpha$

been devoted to developing molecular therapies that enhance both the microvascular perfusion and the function of ischemic or infarcted myocardium.

Stromal cell-derived factor $1 \alpha(\mathrm{SDF}-1 \alpha)$ is a key regulator of physiologic cell motility during both embryogenesis and after birth and is constitutively expressed in a wide variety of cells, including endothelial cells, dendritic cells, and stromal cells. ${ }^{6}$ This powerful chemoattractant is significantly upregulated in response to both myocardial ischemia and infarction and has been shown to effect endothelial progenitor cell proliferation and mobilization to induce vasculogenesis. ${ }^{7,8}$ Experimentally, in both mouse and rat models, peri-infarct myocardial injection of SDF- $1 \alpha$ has been shown to significantly enhance myocardial endothelial progenitor cell density, to increase vasculogenesis and capillary density, and to augment myocardial function by enhancing perfusion, reversing cellular ischemia, increasing cardiomyocyte viability, and ultimately preserving ventricular geometry. ${ }^{8-16}$

An ideal therapy to stem the tide of infarct expansion would be one that could both stiffen and reinforce the fibrotic myocardial scar to reduce the cardiac wall stress in an injured ventricle while simultaneously rescuing the dysfunctional peri-infarct border zone by addressing the microvascular deficit and normalizing the elasticity of the viable myocardium. In this study, it was our hypothesis that angiogenic border zone SDF- $1 \alpha$ therapy would yield a less stiff, more elastic, more mechanically efficient myocardium.

\section{MATERIALS AND METHODS}

\section{Animal Care and Biosafety}

Male CD-1 mice $(\mathrm{n}=18$ ) weighing 25 to $30 \mathrm{~g}$ were obtained from Charles River (Charles River Laboratories International, Inc, Wilmington, Mass) and randomly assigned in equal groups to receive direct intramyocardial injection of either saline solution $(30 \mu \mathrm{L})$ or SDF- $1 \alpha(6 \mu \mathrm{g} / \mathrm{kg}$ in $30 \mu \mathrm{L})$ after infarction or to undergo no infarction. Food and water were provided ad libitum. This investigation was performed in accordance with the Guide for the Care and Use of Laboratory Animals published by the US National Institutes of Health (NIH Publication No. 85-23, revised 1996; www.nap.edu/catalog/5140.html) and was approved by the institutional animal use and care committee of the University of Pennsylvania (protocol No. 709026).

\section{Ischemic Cardiomyopathy Model}

Mice were anesthetized with ketamine hydrochloride [INN ketamine] at $100 \mathrm{mg} / \mathrm{kg}$ and xylazine at $10 \mathrm{mg} / \mathrm{kg}$, intubated with a 22 -gauge catheter, and mechanically ventilated (Hallowell EMC, Pittsfield, Mass). With the animal supine, an anterior thoracotomy was performed in the left fourth intercostal space, and an 8-0 polypropylene suture was placed around the left anterior descending coronary artery midway between the left atrial appendage and left ventricular apex and ligated to produce a large anterolateral myocardial infarction of approximately $30 \%$ of the left ventricle. The extent of infarction has been highly reproducible in our hands, and progression to cardiomyopathy has been well documented. ${ }^{14}$ After ligation, animals were randomly assigned to receive direct intramyocardial injection into the peri-infarct border zone of either saline solution ( $30 \mu \mathrm{L}, \mathrm{n}=6$ ) or SDF- $1 \alpha(6 \mu \mathrm{g} / \mathrm{kg}$ in $30 \mu \mathrm{L}, \mathrm{n}=6)$. Injections were given in 3 divided doses of $10 \mu \mathrm{L}$ to 3 predetermined locations, which consisted of the peri-infarct myocardium to the right and left of the ligating suture and the left ventricular apex. The thoracotomy was then closed, and the animals were extubated and allowed to recover. Buprenorphine hydrochloride [INN buprenorphine] was administered at $0.5 \mathrm{mg} / \mathrm{kg}$ for postoperative analgesia. The SDF- $1 \alpha$ treatment group received subcutaneous injections of $40 \mu \mathrm{g} / \mathrm{kg}$ liquid sargramostim (granulocyte macrophage colony-stimulating factor), diluted in saline solution for a total volume of $100 \mu \mathrm{L}$ immediately postoperatively and on postoperative day 1 . We did not include a control group that received subcutaneous injections of granulocyte macrophage colonystimulating factor because the preponderance of literature has demonstrated no difference between control groups receiving intramyocardial saline solution injection only and groups receiving saline solution injection plus subcutaneous granulocyte macrophage colony-stimulating factor. ${ }^{9,10,12,13}$

\section{Determination of Myocardial Elastic Modulus}

Six weeks after surgery, the animals were killed, and multiple myocardial samples were taken from the peri-infarct border zone and the infarct scar of each animal. Samples were also taken from the left ventricle of noninfarcted control mice $(n=6)$. Tissue specimens were cut into small, thin pieces $(3 \times 3 \times 1 \mathrm{~mm})$, fixed to glass microscope slides, and stored in Dulbecco's modified Eagle medium buffer solution (Gibco; Life Technologies Corporation, Grand Island, NY; Figure 1). Determination of the tissues' elastic moduli was carried out by mechanical testing in an atomic force microscope (Asylum MFP-3D; Asylum Research, Santa Barbara, Calif). Force-distance measurements were performed 20 to 30 times at 1 or more locations on each specimen at the rate of $1 \mathrm{~Hz}$. Each tissue sample was probed an average of 25 times (range, 14-41 times), for a total of 1966 data points. The measurements for each separate group were then aggregated and compared. The atomic force microscope probes' optical sensitivities were determined first on dry glass slides to determine their spring constant and again on glass within the buffer solution to account for absorption of the light by the buffer. Stiffness measurements were then carried out within the buffer. The elastic modulus was determined by analyzing the force curves generated by pressing the probe into the tissue and recording the cantilever deflection. The Herzian-Sneddon model of a cone indenting an elastic half-space has previously been used in similar measurements. ${ }^{17,18}$ In this analysis, the Young modulus of a material $(E)$ is given by the following equation:

$$
E=\frac{d \cdot k \cdot \pi\left(1-v^{2}\right)}{2 \delta^{2} \tan (\alpha)}
$$

where $d$ is the cantilever deflection, $k$ is its bending spring constant, $\nu$ is the material Poisson ratio (assumed to be 0.5 ), $\delta$ is the indentation distance, and $\alpha$ is the half-angle of the cone. MATLAB (The MathWorks, Inc, Natick, Mass) scripts were written to batch process the force curves and find the slope of d versus $\delta^{2}$ lines, which yielded the elastic modulus $E$ (Figure 2).

\section{Statistical Analysis}

The unpaired Student $t$ test was used to compare groups. Values are expressed as mean $\pm \mathrm{SEM}$.

\section{RESULTS}

Force-distance measurements were performed 20 to 30 times at 1 or more locations on each specimen at the rate 


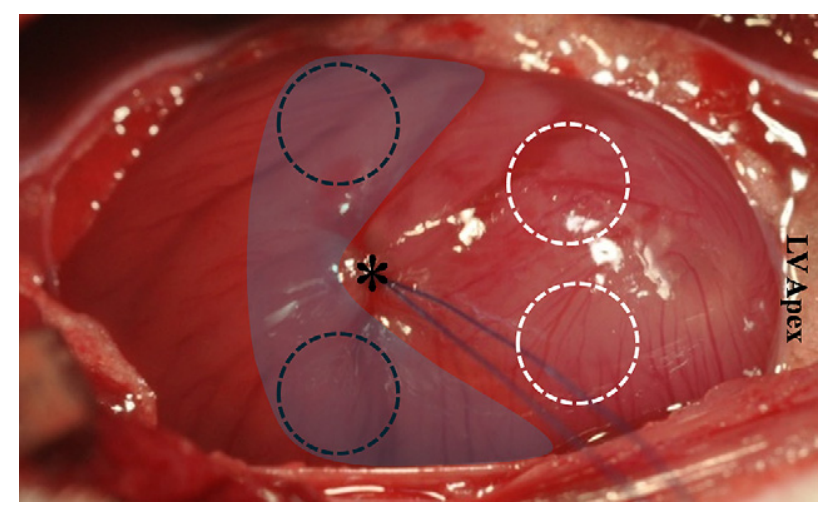

FIGURE 1. Immediately after left anterior descending coronary artery ligation (asterisk indicates exact point of suture ligation), animals were randomly assigned to receive intramyocardial injection of either stromal cellderived factor $1 \alpha$ or saline solution into the peri-infarct border zone (shaded in blue). Dashed circles (black for border zone; white for scar) indicate tissue removed and mounted for atomic force microscopy 6 weeks after surgery. $L V$, Left ventricular.

of $1 \mathrm{~Hz}$. Each tissue sample was probed an average of 25 times (range, 14-41 times), for a total of 1966 data points. Ventricular tissue from noninfarcted mice was significantly more elastic $(60.4 \pm 2.6 \mathrm{kPa} ; P<.02)$ than any of the tissue regions measured from mice that had undergone left anterior descending coronary artery ligation, regardless of whether they had received SDF- $1 \alpha$; however, SDF- $1 \alpha-$ treated peri-infarct border zone most closely approximated the elasticity of normal left ventricle and was significantly more elastic than peri-infarct myocardium treated with saline solution $(109 \pm 22.9 \mathrm{kPa}$ vs $295 \pm 42.3 \mathrm{kPa}$; $P<.0001)$. Consistent with the presumed angiogenic mechanism of action of SDF- $1 \alpha$, the myocardial scar proper, the

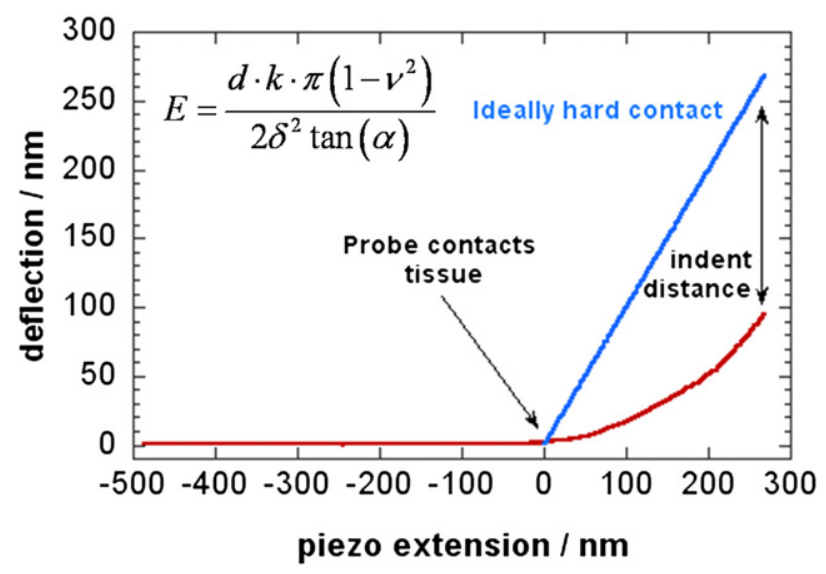

FIGURE 2. In this analysis, the Young modulus of a material is $E$, where $d$ is the cantilever deflection, $k$ is its bending spring constant, $\nu$ is the material Poisson ratio (assumed to be 0.5 ), $\delta$ is the indentation distance, and $\alpha$ is the half-angle of the cone. MATLAB (The MathWorks, Inc, Natick, Mass) scripts were written to batch process the force curves and find the slope of $\mathrm{d}$ (blue) versus $\delta^{2}$ (red) lines, which yielded $\mathrm{E}$.

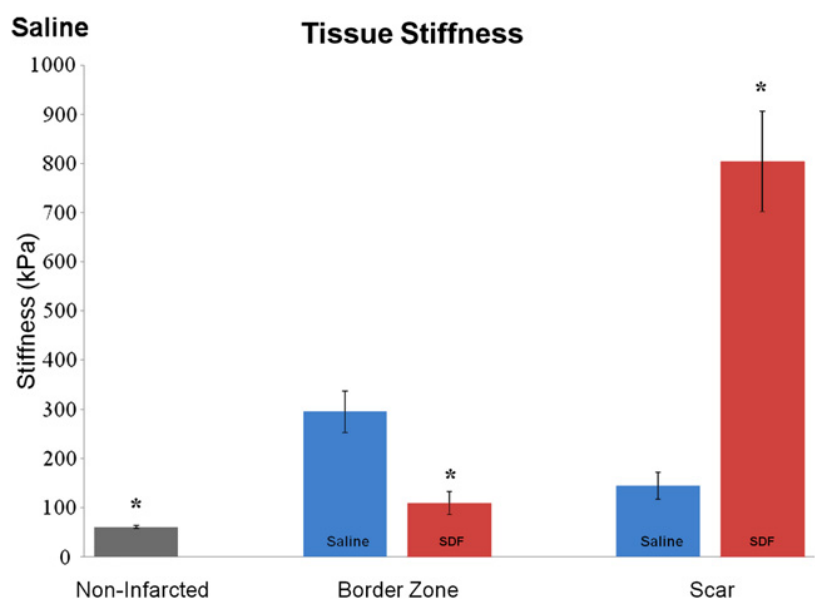

FIGURE 3. By increasing the elasticity of the dysfunctional peri-infarct border zone and stiffening the infarct scar, stromal cell-derived factor $1 \alpha$ $(S D F)$ therapy may confer a mechanical advantage in resisting adverse ventricular remodeling after infarction.

strength of which is dependent of on fibroblast and collagen deposition from vasculature at the peri-infarct edge, was stiffer in SDF- $1 \alpha$-treated animals than in control animals $(804 \pm 102.2 \mathrm{kPa}$ vs $144+27.5 \mathrm{kPa}, P<.0001$; Figure 3). Indentation depth was less than $1 \mu \mathrm{m}$ for nearly all measurements, meaning the base of the cantilever advanced $1 \mu \mathrm{m}$ or less between making contact with the tissue and turning back around. This should not be confused with cantilever deflection or actual penetration into the tissue. All of the measurements were performed at $1 \mathrm{~Hz}$, but the actual velocity depended also on the amount of retraction needed to ensure complete separation of the probe tip from the myocardial tissue sample.

\section{DISCUSSION}

Currently, many groups are exploring the use of injectable or implantable materials to limit infarct expansion and to return the postinfarct myocardial stress distribution to normal. ${ }^{19-25} \mathrm{~A}$ wide range of cell and material types with varying properties have been tested, mostly as a bolster to the infarct scar proper, with the ultimate goal being to reduce strain on the peri-infarct border zone and prevent infarct expansion. In this experiment, we approached this problem from a novel direction. We know that patients with robust angiographic collateralization after an infarct manifest improved regional ventricular function and that SDF- $1 \alpha$ has repeatedly been shown to play a critical role in the rescue of myocardial function, stem cell recruitment to the heart after myocardial infarction, and improved microrevascularization. ${ }^{8-11,14-16,26-30}$ In light of this information, we hypothesized that angiogenic peri-infarct SDF- $1 \alpha$ therapy would yield a less stiff, more elastic, more mechanically efficient myocardium. Because of the preponderance of historical data, we have speculated that 
border zone SDF- $1 \alpha$ therapy, which results in a vastly augmented peri-infarct microvascular bed, will provide an increase in dynamic flow reserve to these areas of maximal mechanical stress. We believe that the enhanced capillarity in the peri-infarct border zone will help to alleviate biomechanical stress, prevent ultrastructural alterations, and improve cardiomyocyte viability, yielding a less stiff, more elastic, more mechanically efficient myocardium, which could ultimately prevent remodeling and improve ventricular performance. In addition, increased vasculature at the peri-infarct edge may intensify myofibroblast accumulation in the infarct scar proper, producing large amounts of extracellular matrix proteins, which will ultimately stiffen and provide mechanical support to the ventricle. ${ }^{31}$

This experiment has demonstrated that SDF- $1 \alpha$ treatment to the peri-infarct border zone at the time of myocardial infarction does in fact re-engineer the evolving myocardial infarct and peri-infarct tissue. Determination of the myocardial elastic moduli was carried out by direct mechanical testing in an atomic force microscope incorporating nearly 2000 data points, and this revealed that peri-infarct border zone tissue treated with SDF- $1 \alpha$ was significantly more elastic than peri-infarct border zone tissue treated with saline solution and more closely approximated normal, noninfarcted ventricle. Additionally, it was found that the infarct scar in SDF- $1 \alpha$-treated animals was much stiffer than the infarct scar in control animals. This is important, because it has been shown that stiffer infarcts are associated with improved ventricular function and less progression toward heart failure. ${ }^{32,33}$ It is wholly possible that the changes seen in SDF- $1 \alpha$-treated border zone actually follow from changes to the scar itself. This would still be consistent with the presumed angiogenic mechanism of action of SDF- $1 \alpha$, because the strength of the myocardial scar is dependent on fibroblast and collagen deposition from vasculature at the peri-infarct edge.

The application of atomic force microscopy to determine the myocardial elastic modulus directly was both a great strength of the study and a potential source of error. When using the atomic force microscope, there are 4 major areas for possible error: indentation velocity, indentation distance, contact point assignment, and data sampling rate. To combat these potential pitfalls, we limited indentation rates to less than $2 \mu \mathrm{m} / \mathrm{s}$, which appropriately explored the elastic rather than the viscoelastic properties of cells and extracellular matrix. ${ }^{34}$ Indentation depth was in fact less than $1 \mu \mathrm{m}$ for most measurements and was performed at a rate of $1 \mathrm{~Hz}^{35,36}$ Contact points assigned through the Domke-Radmacher formula (which allows for the determination of the contact point when the atomic force microscope tip first makes contact with a soft material) rely on accurate selection of the appropriate analysis range $\mathrm{e}^{37}$ and require the data sampling rate to be slowed appropriately to accommodate indentation rates, repeated measurements at each site, and spatial movement to the next site of measurement. Also, tensile strength is a uniaxial measurement that varies with tissue strip orientation, because normal myocardium and healing infarcts are anisotropic tissues. To minimize anisotropic differences in tensile strength, we very carefully tried to dissect the tissues reproducibly and to measure the tissue strips in a uniform direction. ${ }^{38}$

In conclusion, SDF- $1 \alpha$ therapy may confer a mechanical advantage in resisting adverse ventricular remodeling and infarct expansion by increasing the elasticity of the dysfunctional peri-infarct border zone and bolstering the weak, aneurysm-prone scar. Treatment with SDF- $1 \alpha$ also offers a clinically translatable, potentially noninvasive or catheter-based therapy that could be deployed at any point in the time course of ischemic heart disease and can address critical deficits in microvascular perfusion as well as alter myocardial biomechanical material properties.

Use of the University of Pennsylvania Nano/Bio Interface Center instrumentation is acknowledged.

\section{References}

1. Gorman RC, Jackson BM, Burdick JA, Gorman JH. Infarct restraint to limit adverse ventricular remodeling. J Cardiovasc Transl Res. 2011;4:73-81.

2. Jackson BM, Gorman JH, Moainie SL, Guy TS, Narula N, Narula J, et al. Extension of borderzone myocardium in postinfarction dilated cardiomyopathy. $J$ Am Coll Cardiol. 2002;40:1160-71.

3. Rochitte CE, Lima JA, Bluemke DA, Reeder SB, McVeigh ER, Furuta T, et al. Magnitude and time course of microvascular obstruction and tissue injury after acute myocardial infarction. Circulation. 1998;98:1006-14.

4. Tarantini G, Razzolini R, Cacciavillani L, Bilato C, Sarais C, Corbetti F, et al. Influence of transmurality, infarct size, and severe microvascular obstruction on left ventricular remodeling and function after primary coronary angioplasty. Am J Cardiol. 2006;98:1033-40.

5. Heilmann C, Kostic C, Giannone B, Grawitz AB, Armbruster W, Lutter G, et al. Improvement of contractility accompanies angiogenesis rather than arteriogenesis in chronic myocardial ischemia. Vascul Pharmacol. 2006;44: 326-32.

6. De La Luz Sierra M, Yang F, Narazaki M, Salvucci O, Davis D, Yarchoan R, et al Differential processing of stromal-derived factor- $1 \alpha$ and stromal-derived factor$1 \beta$ explains functional diversity. Blood. 2004;103:2452-9.

7. Pillarisetti K, Gupta SK. Cloning and relative expression analysis of rat stromal cell derived factor-1 (SDF-1)1: SDF-1 $\alpha$ mRNA is selectively induced in rat model of myocardial infarction. Inflammation. 2001;25:293-300.

8. Yamaguchi J, Kusano KF, Masuo O, Kawamoto A, Silver M, Murasawa S, et al. Stromal cell-derived factor- 1 effects on ex vivo expanded endothelial progenitor cell recruitment for ischemic neovascularization. Circulation. 2003;107:1322-8.

9. Atluri P, Liao GP, Panlilio CM, Hsu VM, Leskowitz MJ, Morine KJ, et al. Neovasculogenic therapy to augment perfusion and preserve viability in ischemic cardiomyopathy. Ann Thorac Surg. 2006;81:1728-36.

10. Woo YJ, Grand TJ, Berry MF, Atluri P, Moise MA, Hsu VM, et al. Stroma cell-derived factor and granulocyte-monocyte colony-stimulating factor form a combined neovasculogenic therapy for ischemic cardiomyopathy. $J$ Thorac Cardiovasc Surg. 2005;130:321-9.

11. Hiesinger W, Vinogradov SA, Atluri P, Fitzpatrick JR 3rd, Frederick JR, Levit RD, et al. Oxygen-dependent quenching of phosphorescence used to characterize improved myocardial oxygenation resulting from vasculogenic cytokine therapy. J Appl Physiol. 2011;110:1460-5.

12. Atluri P, Panlilio CM, Liao GP, Hiesinger W, Harris DA, McCormick RC, et al. Acute myocardial rescue with endogenous endothelial progenitor cell therapy. Heart Lung Circ. 2010;19:644-54.

13. Hiesinger W, Frederick JR, Atluri P, McCormick RC, Marotta N, Muenzer JR, et al. Spliced stromal cell-derived factor- $1 \alpha$ analog stimulates endothelial 
progenitor cell migration and improves cardiac function in a dose-dependent manner after myocardial infarction. J Thorac Cardiovasc Surg. 2010;140: 1174-80.

14. Hiesinger W, Perez-Aguilar JM, Atluri P, Marotta NA, Frederick JR, Fitzpatrick JR 3rd, et al. Computational protein design to reengineer stromal cell-derived factor- $1 \alpha$ generates an effective and translatable angiogenic polypeptide analog. Circulation. 2011;124(11 Suppl):S18-26.

15. Saxena A, Fish JE, White MD, Yu S, Smyth JW, Shaw RM, et al. Stromal cellderived factor- $1 \alpha$ is cardioprotective after myocardial infarction. Circulation. 2008; 117:2224-31

16. Zhang G, Nakamura Y, Wang X, Hu Q, Suggs LJ, Zhang J. Controlled release of stromal cell-derived factor- $1 \alpha$ in situ increases c-kit+cell homing to the infarcted heart. Tissue Eng. 2007;13:2063-71.

17. Berry MF, Engler AJ, Woo YJ, Pirolli TJ, Bish LT, Jayasankar V, et al. Mesenchymal stem cell injection after myocardial infarction improves myocardial compliance. Am J Physiol Heart Circ Physiol. 2006;290:H2196-203.

18. Domke J, Radmacher M. Measuring the elastic properties of thin polymer films with the atomic force microscope. Langmuir. 1998;14:3320-5.

19. Dobner S, Bezuidenhout D, Govender P, Zilla P, Davies N. A synthetic nondegradable polyethylene glycol hydrogel retards adverse post-infarct left ventricular remodeling. J Card Fail. 2009;15:629-36.

20. Ifkovits JL, Tous E, Minakawa M, Morita M, Robb JD, Koomalsingh KJ, et al. Injectable hydrogel properties influence infarct expansion and extent of postinfarction left ventricular remodeling in an ovine model. Proc Natl Acad Sci U S A 2010;107:11507-12.

21. Landa N, Miller L, Feinberg MS, Holbova R, Shachar M, Freeman I, et al. Effect of injectable alginate implant on cardiac remodeling and function after recent and old infarcts in rat. Circulation. 2008;117:1388-96.

22. Ryan LP, Matsuzaki K, Noma M, Jackson BM, Eperjesi TJ, Plappert TJ, et al. Dermal filler injection: a novel approach for limiting infarct expansion. Ann Thorac Surg. 2009;87:148-55.

23. Singelyn JM, DeQuach JA, Seif-Naraghi SB, Littlefield RB, Schup-Magoffin PJ, Christman KL. Naturally derived myocardial matrix as an injectable scaffold for cardiac tissue engineering. Biomaterials. 2009;30:5409-16.

24. Fitzpatrick JR 3rd, Frederick JR, McCormick RC, Harris DA, Kim AY, Muenzer JR, et al. Tissue-engineered pro-angiogenic fibroblast scaffold improves myocardial perfusion and function and limits ventricular remodeling after infarction. J Thorac Cardiovasc Surg. 2010;140:667-76.

25. Angoulvant D, Fazel S, Weisel RD, Lai TY, Fedak PW, Chen L, et al. Cell-based gene therapy modifies matrix remodeling after a myocardial infarction in tissue inhibitor of matrix metalloproteinase-3-deficient mice. J Thorac Cardiovasc Surg. 2009;137:471-80.
26. Abbott JD, Huang Y, Liu D, Hickey R, Krause DS, Giordano FJ. Stromal cellderived factor- $1 \alpha$ plays a critical role in stem cell recruitment to the heart after myocardial infarction but is not sufficient to induce homing in the absence of injury. Circulation. 2004;110:3300-5.

27. Askari AT, Unzek S, Popovic ZB, Goldman CK, Forudi F, Kiedrowski M, et al. Effect of stromal-cell-derived factor 1 on stem-cell homing and tissue regeneration in ischaemic cardiomyopathy. Lancet. 2003;362:697-703.

28. Tang J, Wang J, Yang J, Kong X, Zheng F, Guo L, et al. Mesenchymal stem cells over-expressing SDF-1 promote angiogenesis and improve heart function in experimental myocardial infarction in rats. Eur J Cardiothorac Surg. 2009;36: 644-50.

29. Ejiri M, Fujita M, Sakai O, Miwa K, Asanoi H, Sasayama S. Development of collateral circulation after acute myocardial infarction: its role in preserving left ventricular function. J Cardiol. 1990;20:31-7.

30. Bonaros N, Sondermeijer H, Wiedemann D, Schlechta B, Schachner T, Schuster M, et al. Downregulation of the CXC chemokine receptor 4/stromal cell-derived factor 1 pathway enhances myocardial neovascularization, cardiomyocyte survival, and functional recovery after myocardial infarction. $J$ Thorac Cardiovasc Surg. 2011;142:687-96. 696.e1-2.

31. Dobaczewski M, Gonzalez-Quesada C, Frangogiannis NG. The extracellular matrix as a modulator of the inflammatory and reparative response following myocardial infarction. J Mol Cell Cardiol. 2010;48:504-11.

32. Pilla JJ, Gorman JH 3rd, Gorman RC. Theoretic impact of infarct compliance on left ventricular function. Ann Thorac Surg. 2009;87:803-10.

33. Wall ST, Walker JC, Healy KE, Ratcliffe MB, Guccione JM. Theoretical impact of the injection of material into the myocardium: a finite element model simulation. Circulation. 2006;114:2627-35.

34. Mahaffy RE, Shih CK, MacKintosh FC, Käs J. Scanning probe-based frequencydependent microrheology of polymer gels and biological cells. Phys Rev Lett. 2000;85:880-3.

35. Buxboim A, Ivanovska IL, Discher DE. Matrix elasticity, cytoskeletal forces and physics of the nucleus: how deeply do cells 'feel' outside and in? J Cell Sci. 2010; 123(Pt 3):297-308.

36. Buxboim A, Rajagopal K, Brown AE, Discher DE. How deeply cells feel: methods for thin gels. J Phys Condens Matter. 2010;22:194116.

37. Rotsch C, Jacobson K, Radmacher M. Dimensional and mechanical dynamics of active and stable edges in motile fibroblasts investigated by using atomic force microscopy. Proc Natl Acad Sci U S A. 1999;96:921-6.

38. Connelly CM, Ngoy S, Schoen FJ, Apstein CS. Biomechanical properties of reperfused transmural myocardial infarcts in rabbits during the first week after infarction. Implications for left ventricular rupture. Circ Res. 1992;71: 401-13. 